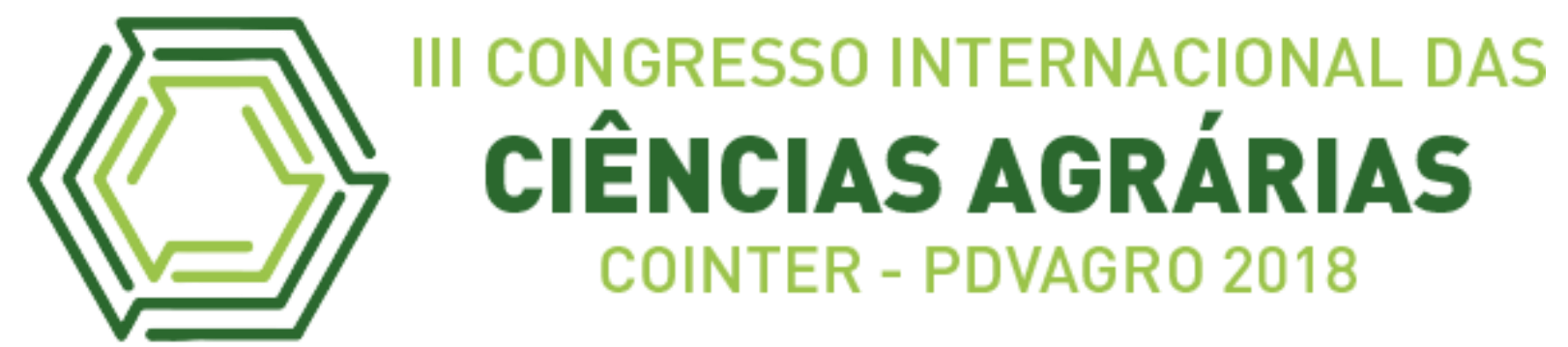

\title{
CRESCIMENTO E PRODUTIVIDADE DE DOIS HÍBRIDOS DE MELANCIA IRRIGADA
}

\section{GROWTH AND PRODUCTIVITY OF TWO HYBRIDS WATERMELON IRRIGATED}

Apresentação: Pôster

\begin{abstract}
Alessandra Monteiro Salviano ${ }^{1}$; Thiago Ferreira Cirilo ${ }^{2}$; Welson Lima Simões ${ }^{3}$; Jony Eishi Yuri ${ }^{4}$; José Maria Pinto ${ }^{5}$
\end{abstract}

\section{DOI: https://doi.org/10.31692/2526-7701.IIICOINTERPDVAGRO.2018.00407}

\section{Introdução}

A melancia (Citrullus lanatus) é cultivada em todo o mundo, pertence à família das cucurbitáceas, e tem como centro de origem o continente africano, tem grande importância em regiões tropicais do mundo. Seus frutos são utilizados tanto na alimentação humana como animal (PEREIRA, 2017).

Dentre os estados brasileiros produtores de melancia destacam-se o Rio Grande do Norte e o Ceará, além do Rio Grande do Sul, Goiás, Bahia e São Paulo que juntos representam mais de $50 \%$ da produção, contribuindo, desta forma, para colocar o país na $4^{\mathrm{a}}$ posição no ranking da produção mundial de melancia, com uma produção de 2 milhões de toneladas (AGRIANUAL, 2017).

Uma das maiores ferramentas agronômicas adotadas para se buscar o máximo potencial produtivo de uma espécie vegetal é a adubação, ou seja, a utilização de fertilizantes que fornecem de forma equilibrada os nutrientes que as plantas necessitam para completar seu ciclo produtivo. As recomendações das adubações, por sua vez, são embasadas nos estudos de resposta à marcha de absorção e exigência nutricional da planta. A necessidade de nutrientes

\footnotetext{
1 Engenheiro agrônomo, D.Sc. em Solos e Nutrição de Plantas, pesquisador da Embrapa Semiárido, alessandra.salviano@embrapa.br

${ }^{2}$ Engenheiro agrônomo, Mestrando em Engenharia Agrícola na UNIVASF, cirilo.ifal@gmail.com

3 Engenheiro agrônomo, D.Sc. em Engenharia Agrícola, pesquisador da Embrapa Semiárido, welson.simoes@embrapa.br

${ }^{4}$ Engenheiro agrônomo, D.Sc. em Fitotecnia, pesquisador da Embrapa Semiárido, jony.yuri@embrapa.br

5 Engenheiro agrônomo, D.Sc. em Engenharia Agrícola, pesquisador da Embrapa Semiárido, josemaria.pinto@embrapa.br
} 
para cada cultura não pode ser deduzida somente pela extração total, mas também pela formulação da marcha de absorção dos nutrientes durante todo seu ciclo produtivo (DAMASCENO, 2011; AGUIAR NETO, 2013).

Este trabalho teve como objetivo avaliar o crescimento, por meio do acúmulo de fitomassa, e a produtividade dos híbridos de melancia Ranger e Red Heaven, cultivados sob irrigação no Vale do Submédio São Francisco.

\section{Fundamentação Teórica}

As curvas de absorção de nutrientes determinadas para algumas espécies de cucurbitáceas têm mostrado comportamento bem semelhante, onde o acúmulo de nutrientes segue o mesmo padrão da curva de acúmulo de matéria seca, geralmente apresentando três fases distintas, sendo a primeira fase uma absorção lenta, seguida de uma intensa absorção até atingir o ponto de máximo, a partir do qual ocorre um pequeno declínio (GRANGEIRO; CECÍLIO FILHO, 2005). A taxa de absorção de nutrientes na cultura da melancia acompanha a taxa de produção de matéria seca, atingindo o máximo na época do desenvolvimento dos frutos, quando então começa a diminuir (VIDIGAL et al., 2009).

\section{Metodologia}

O experimento foi realizado no Campo Experimental de Bebedouro, de propriedade da Embrapa Semiárido, em Petrolina, PE (latitude $9^{\circ} 8^{\prime} 8,9^{\prime \prime} \mathrm{S}$, longitude $40^{\circ} 18^{\prime} 33,6^{\prime \prime} \mathrm{O}$, altitude $365,5 \mathrm{~m}$ ) entre os meses de agosto e outubro de 2017. O solo foi classificado como Latossolo Vermelho Amarelo Distróferrico (SANTOS et al., 2006).

O delineamento experimental adotado foi em blocos inteiramente casualizados, com três repetições. Os tratamentos foram compostos pela combinação de dois híbridos de melancia (Ranger e Red Heaven) e seis épocas de coletas de material vegetal, para análise química, caule, folhas, flores e frutos: 15; 25; 35; 45; 55 e 65 dias após o transplantio - DAT. Nas duas primeiras coletas, aos 15 e 25 DAT, coletaram-se cinco plantas/parcela, sendo nas demais coletas utilizadas apenas uma planta por parcela, com três repetições, totalizando 36 parcelas. Cada parcela experimental apresentava a dimensão de 3,6 $\mathrm{m}$ de comprimento (permitindo o transplantio de seis mudas, assim, o espaçamento adotado foi 0,6 $\mathrm{m}$ entre plantas e 3,0 entre linhas), sendo que dessas, apenas as quatro mudas da parte interna foram consideradas como parcela útil, descartando-se as localizadas nas extremidades. 
A semeadura foi realizada em 10/08/2017 em ambiente protegido, com transplantio aos 10 dias após a semeadura (início da emergência da primeira folha definitiva). Foram utilizadas bandejas de isopor contendo 200 células, preenchidas com substrato comercial "Plantmax HT".

$\mathrm{Na}$ adubação de fundação, com base na análise do solo, foram aplicados $500,0 \mathrm{~kg} \mathrm{ha}{ }^{-1}$ do formulado NPK 06-24-12. Em adubação de cobertura, foram adicionados $90,0 \mathrm{~kg} \mathrm{ha}^{-1} \mathrm{de}$ $\mathrm{N}, 90,0 \mathrm{~kg} \mathrm{ha}^{-1}$ de $\mathrm{K}_{2} \mathrm{O} ; 40,0 \mathrm{~kg} \mathrm{ha}^{-1}$ de $\mathrm{Ca}$; e 10,0 $\mathrm{kg} \mathrm{ha}^{-1}$ de $\mathrm{Mg}$, via fertirrigação, três vezes por semana, ao longo do ciclo, até 7 dias antes da colheita.

A cultura foi mantida no limpo por meio de capinas manuais, quando necessárias. As irrigações foram feitas utilizando o método de gotejamento, com turno diário e lâminas de água calculadas em função da evapotranspiração da cultura, com o auxílio de uma estação meteorológica próxima a área experimental. Foram realizados também os tratos fitossanitários comuns à cultura.

Após a coleta, realizadas na parte da manhã, para evitar que as plantas murchassem até chegar ao laboratório, as plantas foram pesadas para determinação da fitomassa fresca (FFPA), colocadas em estufa com circulação forçada de ar, $65^{\circ} \mathrm{C}$, por 72 horas e pesadas novamente para determinação da fitomassa seca (FSPA).

Os dados de matéria seca, expressos em $\mathrm{g}_{\text {planta }}{ }^{-1}$, foram submetidos à análise de variância e de regressão, por meio do software SISVAR (FERREIRA, 2011).

A colheita foi realizada aos 67 dias após o transplantio, avaliando-se a produtividade comercial $\left(\mathrm{t} \mathrm{ha}^{-1}\right)$, peso do fruto comercial $\left(\mathrm{kg} \mathrm{fruto}^{-1}\right)$ e número de frutos por planta e por hectare.

\section{Resultados e Discussões}

O acúmulo de fitomassa fresca da parte aérea (FFPA) foi lento nos primeiros 25 DAT, aumentando a partir desta época, tendo os híbridos Ranger e Red Heaven atingido um valor máximo estimado de 1.101,53 e 1.405,96 g planta ${ }^{-1}$ aos 49 e 50 DAT, respectivamente (Figura 1). Entre 25 e 35 DAE o aumento em fitomassa fresca da parte aérea apresentou elevado crescimento que resultou num incremento de 357,43 e 490,48 g planta ${ }^{-1}$, enquanto no intervalo entre 35-49 e 35-50 DAT, a parte aérea apresentou acúmulo de 180,94 e 269,26 g planta $^{-1}$ de fitomassa fresca para a Ranger e a Red Heaven, respectivamente. 
Já para o acúmulo de fitomassa seca da parte aérea (FSPA) foi lento nos primeiros 25 DAT, aumentando a partir desta época, tendo os híbridos Ranger e Red Heaven atingido valor máximo estimado de 129,21e 163,81 $\mathrm{g} \mathrm{planta}^{-1}$ aos 51 e 49 DAT, respectivamente (Figura 2). Entre 25 e 35 DAT o aumento em fitomassa seca da parte aérea apresentou elevado crescimento que resultou num incremento de 42,5 e 57,4 $\mathrm{g} \mathrm{planta}^{-1}$, enquanto no intervalo entre 35 - 51 e 35 - 49 DAT, a parte aérea apresentou acúmulo de 25,98 e 29,96 g planta ${ }^{-1}$ de fitomassa seca para a Ranger e a Red Heaven, respectivamente.

Almeida et al. (2014), estudando o acúmulo de matéria seca do cultivar Quetzali de melancia, observaram que a melancieira (folhas, ramos e frutos) teve incremento médio na fitomassa seca total de $1.123,49 \mathrm{~g}$ planta $^{-1}$ entre 24 e 64 DAE. O acúmulo total de fitomassa seca pela planta entre 1 e 51 DAE foi de $1.131,72 \mathrm{~g} \mathrm{planta}^{-1}$. Entre 24 e 34 DAE o aumento em fitomassa seca da parte aérea, resultou num incremento de 69,40 g planta ${ }^{-1}$. No intervalo entre 34 e 64 DAE, a parte aérea apresentou elevado crescimento o que culminou num acúmulo de $1.054,09 \mathrm{~g}_{\text {planta }}{ }^{-1}$ de fitomassa seca.

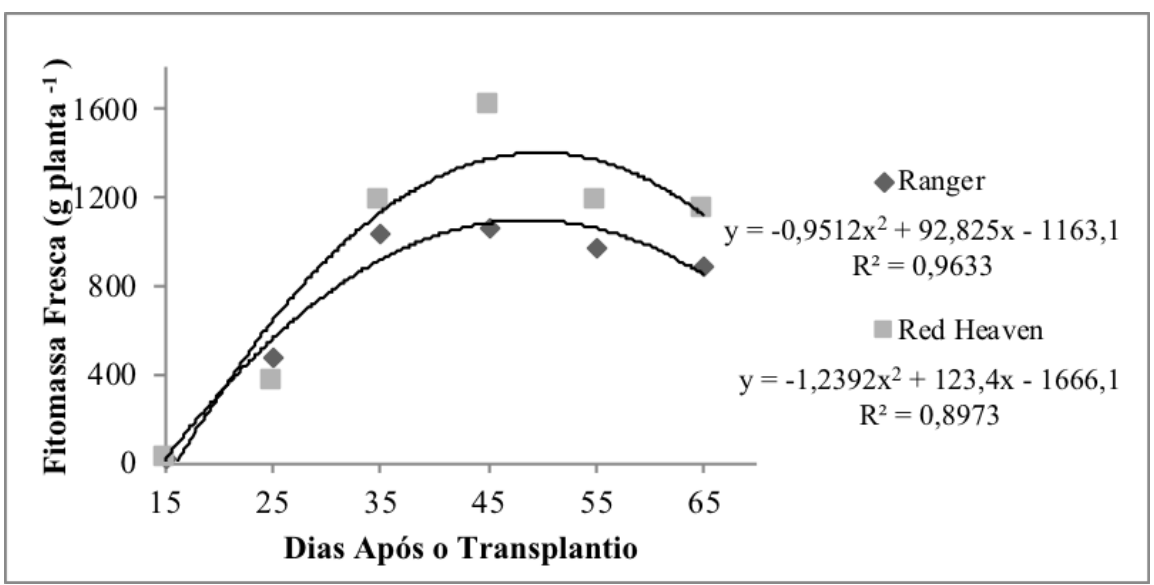

Figura 1. Acúmulo de fitomassa fresca da parte aérea (FFPA) de dois híbridos de melancia cultivados nas condições do Vale do Submédio São Francisco, em Petrolina-PE. 


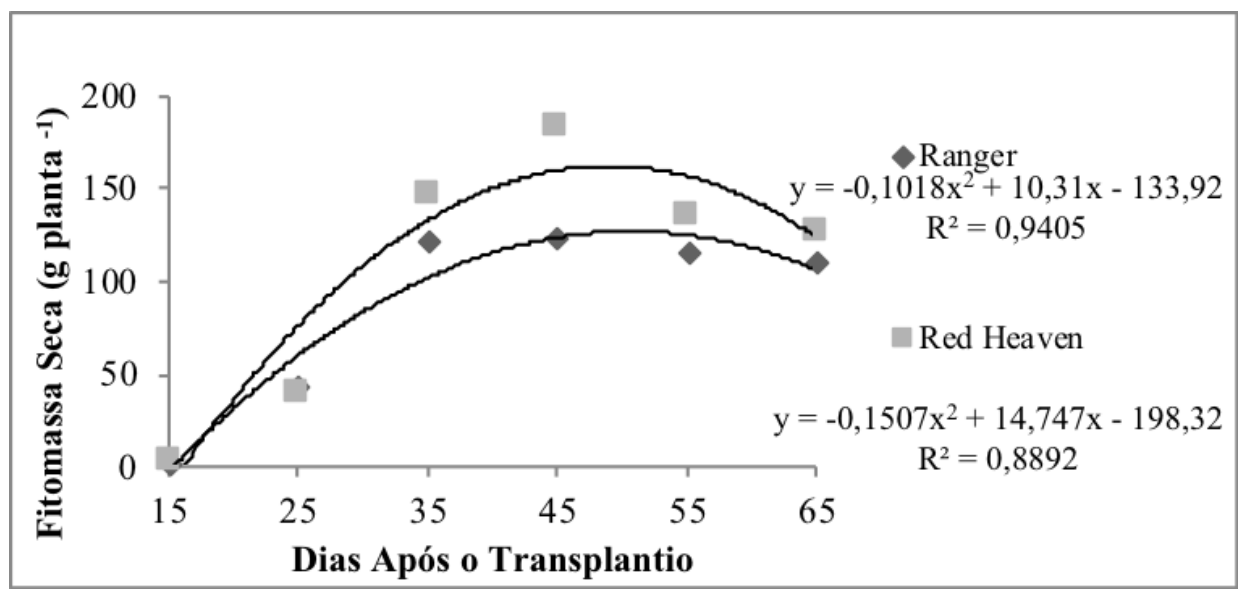

Figura 2. Acúmulo de fitomassa seca da parte aérea (FSPA) de dois híbridos de melancia cultivados nas condições do Vale do Submédio São Francisco, em Petrolina-PE.

A produtividade comercial obtida foi de $53,8 \mathrm{t} \mathrm{ha}^{-1}$ para a cultivar Ranger e 57,2 $\mathrm{t} \mathrm{ha}^{-1}$

Red Heaven. Carmo et al. (2015), sob condições de temperaturas elevadas, observaram produtividades comerciais para as cultivares Crimson Sweet e Explorer com 63,2 e 60,1 t ha-1, respectivamente. No mesmo período Silva et al. (2017) verificaram produtividades oscilando entre 40,8 e 67,8 t ha-1 . A cultivar Ranger produziu 5.617 frutos/ha com peso médio de 9,7 kg, enquanto a cultivar Red Heaven produziu 5.246 frutos, com peso médio de $11 \mathrm{~kg}$ (Tabela 1). Cardoso e Isaac (2010) relatam que os frutos comerciáveis estão entre 5,5 kg a 12,0 kg.

Tabela 1. Produtividade, peso e número de frutos comerciais de cultivares de melancia no Submédio do Vale do São Francisco. Petrolina, 2017.

\begin{tabular}{cccc}
\hline Cultivares & Produtividade $\left(\mathrm{t} \mathrm{ha}^{-1}\right)$ & Peso fruto $(\mathrm{kg})$ & Número de frutos ha $^{-1}$ \\
\hline Ranger & 53,8 & 9,7 & 5.617 \\
Red Heaven & 57,2 & 11,0 & 5.246 \\
\hline CV. $(\%)$ & 9,9 & 11,7 & 13,2 \\
\hline
\end{tabular}

\section{Conclusões}

Ambas as cultivares apresentaram boas produtividades, sendo recomendadas para o cultivo nas condições edafoclimáticas do município de Petrolina - PE.

A cultivar Red Heaven apresentou maior produção de fitomassas fresca e seca da parte vegetativa e maior produtividade.

O período compreendido entre os 25 e 35 DAT é o de maior acúmulo de massa seca da parte vegetativa pelas cvs. de melancia avaliadas.

\section{Referências}


AGRIANUAL. Anuário estatístico da agricultura brasileira. São Paulo: FNP, 2017. p. 322-324.

AGUIAR NETO, P. Crescimento e acúmulo de nutrientes em cebola, melão e melancia nos estados do Rio Grande do Norte e Pernambuco. 2013. 205f. Tese (Doutorado em Agronomia - Fitotecnia) - Universidade Federal Rural do Semiárido - UFERSA, Mossoró, 2013.

ALMEIDA, E. I. B; NÓBREGA G. N.; CORRÊA, M. C. de M.; PINHEIRO, E. A. R.; ARAÚJO, N. A. de Crescimento e marcha de absorção de micronutrientes para a cultivar de melancia Crimson Sweet. Revista Agroambiente, v 8, n 1, p 74-80, janeiro-abril, 2014.

DAMASCENO, Ana Paula Alves Barreto. Production, growth and nutrient uptake of cantaloupe melon type "Harper" fertilized with N and K. 2011. 119 f. Dissertação (Mestrado em Irrigação e Drenagem) - Universidade Federal Rural do Semi-Árido, Mossoró, 2011.

GRANGEIRO L. C.; CECÍlLIO FILHO A. B. Acúmulo e exportação de macronutrientes em melancia sem sementes. Horticultura Brasileira, Brasília, v. 23, p. 763-767, 2005.

CARDOSO, M.C.; ISAAC, A.C. Cultivares de melancia recomendadas para o plantio em "terra firme" no Estado do Amazonas. Manaus: Embrapa Amazônia Ocidental. 5p. 2010. (Embrapa Amazônia Ocidental. Comunicado Técnico, 90).

CARMO2, I. L. G. da S.; SILVA, E. S.da; MONTEIRO NETO, J. L. L.; TRASSATO, L. B.; MEDEIROS, R. D. de; PORTO, D. S. Desempenho agronômico de cultivares de melancia no cerrado de Boa Vista, Roraima. Revista Agro@mbiente On-line, v. 9, n. 3, p. 268-274, julho-setembro, 2015

FERREIRA, D.F. Sisvar: a computer statistical analysis system. Ciência e Agrotecnologia, Lavras, v. 35, n.6, p. 1039-1042, 2011.

PEREIRA, D. R. M. Desempenho agronômico da melancia por semeadura direta e transplantio e mudas. 2017. 12 f. Dissertação (Mestrado em Agronomia: Produção vegetal) - Universidade federal de Goiás, Goiânia, 2017.

SANTOS, H.G.; JACOMINE, P.K.T.; ANJOS, L.H.C.; OLIVEIRA, V.A.; OLIVEIRA, J.B.; COELHO, M.R.; LUMBRERAS, J.F.; CUNHA, T.J.F. (Eds.) Sistema brasileiro de classificação de solos. 2. ed. Rio de Janeiro: Embrapa Solos. 2006. 306p.

SILVA, E.S.; CARMO, I.L.G.S.; MONTEIRO NETO, J.L.L.; MEDEIROS, R.D.; MENEZES, P.H.S.; RODRIGUEZ, C.A. Características agronômicas de cultivares de melancia nas condições do cerrado de Roraima, Brasil. Scientia Agropecuária, Trujillo, v. 3, n. 8, p. 193-201, 2017.

VIDIGAL, S. M.; PACHECO, D. D.; COSTA, E. L.; FACION, C. E. Crescimento e acúmulo de macro e micronutrientes pela melancia em solo arenoso. Revista Ceres, Viçosa, v. 56, n. 1, p. 112-118, 2009. 
